\title{
Evaluation of Neonatal Cardiopulmonary and Anthropometric Indices: A Key Predictive Clinical Biomarker for Neonatal Health Status
}

Gideon T. Olowe

Delta State University, Abraka

Simon I Ovuakporaye

Delta State University, Abraka

Bartholomew C. Nwogueze

Evangel University

Mega 0. Oyovwi ( $\square$ megalect@gmail.com )

Achievers University

Emmanuel I. Odokuma

Delta State University, Abraka

Victor Emojevwe

University of Medical Sciences, Ondo,

\section{Research Article}

Keywords: Cardio-pulmonary, Anthropometry, Neonatal survival, Preterm neonates, Term neonates

Posted Date: October 12th, 2021

DOl: https://doi.org/10.21203/rs.3.rs-939470/v1

License: (1) This work is licensed under a Creative Commons Attribution 4.0 International License.

Read Full License 


\section{Abstract \\ Background}

Neonatal mortality has been reported as a major societal health menace across the globe. Hence, this study, which adopted a hospital-based cross-sectional type of experimental research design, aimed at examining the clinical indication of some selected cardiopulmonary and anthropometric indices as key predictive clinical biomarkers for neonatal survival. The subjects were divided into three groups; experimental Group 1 consisted of 80 pre-term neonates within 28 weeks; experimental Group 2 consisted of 80 pre-term neonates within 33 weeks; and the control group, which consisted of 80 apparently healthy, term neonates. For each subject selected, cardio-pulmonary parameters and anthropometric variables were obtained daily and compared. ANOVA, correlation coefficients, and linear regression were used to compare statistical measures. A discrimination accuracy test of previous records using cut points available from previous models was conducted for ease of estimating the possibility of neonatal survival from assayed variables.

\section{Results}

Following data collection, sorting, and analysis, the study found a statistically significant decrease $(\mathrm{p}<$ 0.05 ) in average systolic blood pressure (SBP) values of preterm neonates when compared with term neonates. This, however, was the reverse for DBP, which was proved to have increased in preterm neonates compared to term neonates. The study also observed a statistically significant decrease $(\mathrm{p}<$ 0.05 ) in RR and OSL levels of preterm neonates compared to term neonates.

\section{Conclusion}

In conclusion, cardiopulmonary and anthropometric status could be useful predictive biomarkers in clinical trials to provide insight into the extent of compromise in newborn health. This will help to minimize the death of neonates by ensuring a better treatment protocol/regimen is given. A corroborative study with an event-driven approach that assays more molecular or other non-physiological variables is recommended.

\subsection{Introduction}

Neonatal period is the most vulnerable time as they face the highest risk of dying in their first month of life, with the majority dying in the first week. ${ }^{1}$ Expanded body of evidence have shown that about 14 million of the 130 million children born each year die within the first 28 days of life. ${ }^{2,3}$

The first week accounts for three-quarters of neonatal deaths, with more than a quarter occurring within the first 24 hours. ${ }^{2}$ Neonatal deaths account for $40 \%$ of all deaths in children under the age of five 
worldwide. ${ }^{2}$ As a result, efforts in developed countries to meet the United Nations' development goals of halving childhood mortality by two-thirds by 2020 focused on reducing neonatal deaths. ${ }^{1}$

Childhood mortality is frequently used as a broad indicator of social development or a particular indicator of a country's health conditions in this context. In the midst of this, child health programs, particularly neonatal health, are frequently overlooked. ${ }^{1}$ Until early childhood, neonates' cardio-respiratory systems go through series of physiological changes. The cardiovascular and pulmonary anomalies are the most common congenital abnormalities in newborns. ${ }^{4}$ As a result of this, cardiovascular and respiratory physiology in neonates differ from that of older children and adults. Deaths in the NICU (neonatal intensive care unit) due to cardio-pulmonary pathologies are found to be the greatest in developing and developed countries. ${ }^{5}$

Despite this, there has been little quantification of predictive markers to predict neonatal survival and predictors that can actually suggest the neonate's state of health in terms of the amount of treatment that should be given. As a result, physiological functions in neonates must be investigated as potential tools for predicting neonatal survival using cardiopulmonary and anthropometric parameters. These markers include blood pressure, pulse rate, oxygen saturation level, and respiratory rate which are the regular cardio-pulmonary parameters in NICUs in developing countries, weight, length, and head circumference are the regular anthropometric parameters ${ }^{6,5}$ in maternity clinics.

In this context, this study aimed at determining the changes in cardiopulmonary variables [SBP (Systolic Blood Pressure), DBP (Diastolic Blood Pressure), PR (Pulse Rate), RR (Respiratory Rate) and OSL (Oxygen Saturation Level)] in term and pre-term neonates, investigating the changes in anthropometric parameters [Weight, Length, HC (Head Circumference)] in term and pre-term neonates, establishing a relationship between cardiopulmonary and anthropometric variables in preterm and term neonates; and developing a multiple linear regression model from which neonatal survival can be predicted using cardio-pulmonary and anthropometric parameters.

\subsection{Materials And Methods}

2.1 Study Location: This study was conducted at the NICU, Central Hospital Warri, Delta State, Nigeria. Delta state occupies a land area of 16,842 square kilometers (6,503 square kilometers) between longitude $50.00 \otimes$ and $60.45 \otimes$ East and latitude 50.0冈 and 60.30冈 North of the equator. With an approximate population of $4,112.445$ people $\left(2,069,309\right.$ males and $2,043,136$ females), it is a densely populated area. ${ }^{7}$

2.2 Study Population and Sample Size determination: The study population was derived from the total number of neonates admitted in the NICU, Central Hospital Warri throughout the study duration. This was estimated at 3,750 neonates; this value comprised those on admission throughout their neonatal period and those discharged before they completed 28days of life for one reason or the other. From this number, a calculated sample was obtained using a single population proportion formula by considering $p=50 \%$, 
$\mathrm{Cl}=95 \%$ and $5 \%$ margin of error. Finally, to compensate for non-response rate, $10 \%$ was added. Thus, to conduct this study a sample size of 240 was used

2.3 Study Design: A hospital-based cross-sectional type of experimental research design was adopted for this study within the period of six (6) months. Data were obtained from a cross section of neonates on admission in the NICU, Central Hospital Warri. The subjects were divided into three groups; Experimental Group 1 consisting of 80 pre-term neonates within 28-32weeks, Experimental Group 2 consisting of 80 pre-term neonates within 33-36weeks, and Control Group which consisted of 80 apparently healthy, term neonates. For each subject selected, cardio-pulmonary parameters (BP, PR, RR, and OSL) and Anthropometric variables (Weight, Length, and $\mathrm{HC}$ ) were obtained daily and compared for changes across obtained data as earlier described in a previous study. ${ }^{3}$

2.4 Sampling Technique: Using the simple random sampling technique, preterm neonates' of 28-36weeks gestation was drawn from the population of admitted neonates. As a rule, at least 10 events per potential predictor are required to build a prediction model. ${ }^{31}$ Hence, the expected number of events was adequate to build a robust prediction model.

2.5 Eligibility Criterion: Only preterm neonates (28-36 weeks gestation) admitted into the NICU, Central Hospital Warri, Delta State were eligible to participate in the study. Neonates of mothers who are under intra-partum antibiotics as well as babies with prior antibiotic therapy for present illness were excluded from this study. Neonates with respiratory distress, who manifested signs with difficulty in breathing, were also excluded from this study.

\subsection{Data Collection}

\subsubsection{Determination of Cardio-Pulmonary Parameters}

\section{Blood Pressure and Pulse Rate (PR)}

Resting systolic and diastolic blood pressure were measured using the electronic sphygmomanometer (Omron Intelli sense M6 Comfort, Japan) with a neonatal blood pressure cuff that covered up to $40 \%$ of the preferred limb (right arm). The cuff was applied to the upper arm (left or right) of the neonate at a lying position. ${ }^{16}$ The heart rate was concomitantly recorded (in beats per minute) from the sphygmomanometer reading during blood pressure measurement. The neonates were required to rest in a quiet atmosphere for 30 minutes prior to assessment and recording as prescribed by. ${ }^{9}$

\section{Determination of Oxygen Saturation Level}

Oxygen Saturation level was measured with a pulse oximetry device as earlier described by, ${ }^{10}$ which involves a non-invasive technique for measuring arterial oxygen saturation level. The device includes a sensor that measures light absorption of haemoglobin and represents arterial oxygen saturation, $\mathrm{SpO}_{2}$. It quantifies the "Relative amount of light absorbed by oxyhemoglobin and deoxyhemoglobin", comparing 
in any case the amount of light emitted. This comparison is then converted to a ratio and expressed in percentage of $\mathrm{SpO}_{2}$.

\section{Determination of Respiratory Rate (RR)}

A person's respiratory rate is the number of breaths he or she takes per minute. This was measured in the new-born when at rest by counting the number of breaths by counting how many times the chest rises in one minute as prescribed in a previous study. ${ }^{11}$

\subsubsection{Determination of Anthropometric Parameters}

Weight, length, and head circumference were calculated using the methods defined by the American College of Sports Medicine. ${ }^{12}$ Accordingly, all the anthropometric parameters were collected from the neonates in a supine position. The length and head circumference were measured with the aid of a flexible rubber measuring tape. For head circumference, the tape was wrapped snugly around the circumference of the head from the most prominent part of the forehead (often 1-2 fingers above the eyebrow) to the widest part of the back of the head. With the subject dressed in light clothes without shoes, shoulder relaxed, the arms hanged loosely, the heels and occiput in contact with the hard lying floor, and the length was measured in centimeters from the head to the soles of the feet using a measuring tape. Still dressed as above, the weights of subjects were measured in grams ( $\mathrm{g}$ ) using an electronic weighing scale (Cardinal Scale Manufacturing Co., Webb Area, MO).To ensure specificity, each neonate was assessed three (3) times.

\subsection{Statistical Analysis}

Statistical measure of Association (Correlation) was used to establish a relationship between measured variables. Confidence levels for all statistical based calculations were set at $p<0.05$. Were applicable, one-way ANOVA was used to check differences in mean between groups. All statistical tests were automated, using the graph pad prison (version 8.0).

\subsection{Results}

\subsection{Changes in Cardiovascular status of Term and Pre-Term Neonates}

The changes in cardiovascular variables of term and pre-term neonates are shown in Table 1. Accordingly, pre-term of week 28-32 and Week 33-36 respectively revealed a significant $(p<0.05)$ increased in blood pressure as indicated by increased SBP $(\mathrm{mmHg})$ and DBP $(\mathrm{mmHg})$ level with corresponding decreased in PR (BPM) at week 28-32 when compared to term neonate. Notably, there was an increase in PR of pre-term neonate (Week 33-36) as related to term neonate 


\begin{tabular}{|c|c|c|c|c|c|}
\hline \multirow{2}{*}{ Parameters } & \multirow[t]{2}{*}{ Term (Control) } & \multicolumn{2}{|l|}{ Pre-Term (Exp.) } & \multirow{2}{*}{$\begin{array}{l}\text { ANOVA } \\
\text { (p-value) }\end{array}$} & \multirow{2}{*}{ Remark } \\
\hline & & Week 28-32 & Week 33-36 & & \\
\hline SBP $(\mathrm{mmHg})$ & $100.06 \pm 2.46$ & $114.24 \pm 2.89 *$ & $99.30 \pm 2.11$ & 0.0307 & Significant \\
\hline $\mathrm{DBP}(\mathrm{mmHg})$ & $78.16 \pm 0.98$ & $80.01 \pm 1.61$ & $83.13 \pm 1.31 *$ & 0.0041 & Significant \\
\hline PR (BPM) & $139.90 \pm 4.18$ & $121.10 \pm 3.91$ & $155.17 \pm 6.02^{*}$ & 0.0006 & Significant \\
\hline
\end{tabular}

SBP-Systolic Blood pressure. DBP-Diastolic blood pressure, PR-Pulse rate. ${ }^{\star} p<0.05$ significant when compared to the control

\subsection{Changes in Anthropometric status of Term and Pre- Term Neonates}

As shown in Table. 2, one-way ANOVA followed by post-hoc test showed that pre-term of week 28-32 and Week 33-36 respectively revealed a significant $(p<0.05)$ decreased in neonatal weight $(\mathrm{kg})$, length $(\mathrm{cm})$ and $\mathrm{HC}(\mathrm{cm})$ when compared to term neonate throughout the period of the study.

Table 2

ANOVA Result for Changes in Anthropometric status of Term and Pre-Term Neonates

\begin{tabular}{|c|c|c|c|c|c|}
\hline \multicolumn{5}{|l|}{ Parameters } & \multirow[t]{3}{*}{ Remark } \\
\hline \multirow[t]{2}{*}{ Term (Control) } & \multicolumn{2}{|c|}{ Pre-Term (Exp.) } & & ANOVA & \\
\hline & $\begin{array}{l}\text { Week 28- } \\
32\end{array}$ & $\begin{array}{l}\text { Week 33- } \\
36\end{array}$ & & $\begin{array}{l}\text { value)ANOVA } \\
\text { (p-value) }\end{array}$ & \\
\hline Birth Weight (Kg) & $3.44 \pm 0.43$ & $2.48 \pm 0.25$ & $2.76 \pm 0.31$ & 0.0017 & Significant \\
\hline Length (cm) & $50.6 \pm 7.23$ & $42.9 \pm 6.81$ & $48.8 \pm 9.16$ & 0.0050 & Significant \\
\hline $\begin{array}{l}\text { Head Circumference } \\
(\mathrm{cm})\end{array}$ & $35.34 \pm 3.31$ & $28.52 \pm 2.96$ & $30.18 \pm 2.56$ & 0.0012 & Significant \\
\hline
\end{tabular}




\subsection{Comparative Changes in pulmonary status of Term and Pre-Term Neonates}

As shown in Fig. 1a-b, one-way ANOVA followed by post-hoc test showed that pre-term of week 28-32 and Week 33-36 respectively revealed a significant $(p<0.05)$ decreased in RR (Cycle/Min) $(1 a)$, and OSL (\%) (1b) when compared to term neonate. However, pre-term of week 28-32 shows a highly significant $(p<$ 0.05) decreased in RR and OSL when compared pre-term of Week 33-36. I

\subsection{Relationship between Cardiovascular status in Neonates}

Pearson's correlation coefficient $(R)$ between various neonatal cardiovascular measurements are presented in Fig. 2. All of the neonatal cardiovascular parameters such as systolic blood pressure (SBP), Diastolic blood pressure (DBP), and pulse rate (PR) had a positive correlation between each parameters $(p<0.05)$. The correlation coefficient $(R)$ value ranged from 0.16 to 1.00 . The highest correlation was observed on both SBP ( $r=1.00)$, DBP $(r=1.00)$, and PR $(r=1.00)$.

\subsection{Respiratory status in Neonates}

Pearson's correlation coefficient $(R)$ between various neonatal respiratory measurements are presented in Fig. 3. All of the neonatal respiratory parameters such as respiratory rate (RR), and oxygen saturation level (OSL) had a positive statistically significant correlation between each parameters $(p<0.05)$. RR, and OSL had a positive statistically significant correlation when correlated with each other $(p<0.05)$. The correlation coefficient $(R)$ value ranged from 0.5 to 1.00 . The highest correlation was observed on both RR $(r=1.00)$, and OSL $(r=1.00)$.

\subsection{Relationship between Neonatal Anthropometric status in Neonates}

Pearson's correlation coefficient $(R)$ between various neonatal anthropometric measurements are presented in Fig. 4. All of the anthropometric parameters such as birth weight $(\mathrm{Kg})$, length $(\mathrm{cm})$ and head circumference $(\mathrm{HC})$ from the neonates had a positive statistically significant correlation between each parameters $(p<0.05)$. Weight, length and $\mathrm{HC}$ had a positive statistically significant correlation when correlated with each of the anthropometric measurement $(p<0.05)$. The correlation coefficient $(R)$ value ranged from 0.42 to 1.00. The highest correlation was observed on both BW $(r=1.00)$, Length $(r=1.00)$, and $\mathrm{HC}(r=1.00)$.

\subsection{Prediction of RR from Neonatal cardiovascular Parameters in Preterm Neonates using multiple linear regression}

In predicting or estimating RR from neonatal cardiovascular measurements in pre-term neonates, a multiple linear regression analyses were carried out and the report is shown in (Table 3). Notably, It was 
observed that the significant correlation $(r=3.013, p=0.0027 ; p<0.05)$ was obtained when neonatal MAP were entered in multiple linear regression analysis. Collectively, on multiple linear regression analysis, MAP had significant correlation with RR $(p<0.05)$, whereas SBP and DBP had no significant correlation with RR ( $p>0.05)$. Therefore, the most important significant correlation was obtained from MAP $(\mathrm{MAP}=3.013, p=0.0027 ; p<0.05)$. Therefore, the best regression model to predict $\mathrm{RR}$ of neonate was $=-\mathrm{RR}$ $(\mathrm{BPM})=18.21+[0.011 \times \mathrm{MAP}](r=3.013, p=0.0027 ; p<0.05)$.

Table 3

Multiple Regression that Estimates RR from SBP, DBP and MAP in Preterm Neonates, Given Body Weight

\begin{tabular}{|lllllll|}
\hline$R R$ & Reg. Eqn. & SEM & t-stat & p-value & $\mathbf{R}^{2}$ & Remark \\
\hline & $\mathrm{Y}=\mathrm{b}_{\mathbf{0}}+\mathrm{b}_{\mathbf{1}} \mathrm{x}_{\mathbf{1}}+\mathrm{b}_{\mathbf{2}} \mathrm{x}_{\mathbf{2}}$ & & & & & \\
$\mathrm{Y}$ & $37.65+(0.006) * \mathrm{SBP}+(-1.09) * \mathrm{BW}$ & 3.8098 & 9.882 & 5.8577 & 0.0201 & Insignificant \\
$\mathrm{Y}$ & $37.43+(0.011) * \mathrm{DBP}+(-1.03) * \mathrm{BW}$ & 5.7466 & 6.514 & 5.9685 & 0.0200 & Insignificant \\
$\mathrm{Y}$ & $18.21+(0.011) * \mathrm{MAP}+(-0.06) * \mathrm{BW}$ & 3.1084 & 3.013 & 0.0027 & 0.0011 & Significant \\
\hline
\end{tabular}

$S B P=$ Systolic Blood Pressure, $D B P=$ Diastolic Blood Pressure, MAP = Mean Arterial Pressure and RR = Respiratory rate $Y=$ Predicted Neonatal Serum Variable $(S B P, D B P$ or $M A P), b_{0}=$ regression intercept (constant), $b_{1}=$ regression coefficient for predicted marker (Constant), $b_{2}=$ regression coefficient for Preterm neonate's body weight (Constant), $x_{1}=$ known levels of assayed marker [SBP, DBP or MAP], and $x_{2}=$ Known Neonate's Body Weight (Kg).

\subsection{Prediction of RR from Neonatal cardiovascular Parameters in Term Neonates using multiple linear regression}

In predicting or estimating RR from neonatal cardiovascular measurements in pre-term neonates, a multiple linear regression analyses were carried out. Notably, It was observed that the significant correlation $(r=7.021, p=0.0500 ; p<0.05)$ was obtained when neonatal SBP were entered in multiple linear regression analysis. Collectively, on multiple linear regression analysis, SBP had significant correlation with RR $(p<0.05)$, whereas DBP and MAP had no significant correlation with RR $(p>0.05)$. Therefore, the most important significant correlation was obtained from SBP (SBP $=r=7.021, p=0.0500 ; p<0.05)$. Interestingly, the best regression model to predict RR of term neonate was $=-$ RR $(B P M)=41.05+[0.012 \times$ $\operatorname{SBP}](r=7.021, p=0.0500 ; p<0.05)$ (Table 4). 
Table 4

Multiple Regression that Estimates RR from SBP, DBP and MAP in Term Neonates, Given Body Weight

\begin{tabular}{|cllllll|}
\hline$R R$ & Reg. Eqn. & SEM & t-stat & P-value & $R^{2}$ & Remark \\
\hline & $\mathrm{Y}=\mathrm{b}_{\mathbf{0}}+\mathrm{b}_{1} \mathrm{x}_{\mathbf{1}}+\mathrm{b}_{\mathbf{2}} \mathrm{x}_{\mathbf{2}}$ & & & & & \\
$\mathrm{Y}$ & $41.05+(0.012) * \mathrm{SBP}+(-1.10) * \mathrm{BW}$ & 4.1016 & 7.021 & 0.0500 & 0.1121 & Significant \\
\hline $\mathrm{Y}$ & $38.41+(0.001) * \mathrm{DBP}+(-1.11) * \mathrm{BW}$ & 5.0117 & 6.120 & 0.9001 & 0.3252 & Insignificant \\
\hline $\mathrm{Y}$ & $33.10+(0.000) * \mathrm{MAP}+(-1.00) * \mathrm{BW}$ & 3.2324 & 4.214 & 0.1002 & 0.0144 & Insignificant \\
\hline
\end{tabular}

$S B P=$ Systolic Blood Pressure, $D B P=$ Diastolic Blood Pressure, $M A P=$ Mean Arterial Pressure and $R R=$ Respiratory rate $Y=$ Predicted Neonatal Serum Variable $(S B P, D B P$ or $M A P), b_{0}=$ regression intercept (constant), $b_{1}=$ regression coefficient for predicted marker (Constant), $b_{2}=$ regression coefficient for Preterm neonate's body weight (Constant), $x_{1}=$ known levels of assayed marker [SBP, DBP or MAP], and $x_{2}=$ Known Neonate's Body Weight (Kg).

\subsection{Prediction of OSL from Neonatal cardiovascular Parameters in Term and Pre-term Neonates using multiple linear regression}

In predicting or estimating OSL from neonatal cardiovascular measurements in pre-term neonates, a multiple linear regression analyses were carried out. However, on multiple linear regression analysis, SBP, DBP and MAP had no significant correlation with OSL ( $p>0.05)$. Moreso, no regression model was noted to predict OSL of term and pre-term neonate (Table 5 and 6 ).

Table 5

Multiple Regression that Estimates OSL from SBP, DBP and MAP in Pre-Term Neonates, Given Body

\begin{tabular}{|lllllll|}
\hline OSL & Reg. Eqn. & SEM & t-stat & p-value & $\mathbf{R}^{2}$ & Remark \\
\hline & $\mathrm{Y}=\mathrm{b}_{\mathbf{0}}+\mathrm{b}_{\mathbf{1}} \mathbf{x}_{\mathbf{1}}+\mathrm{b}_{\mathbf{2}} \mathbf{x}_{\mathbf{2}}$ & & & & & \\
\hline $\mathrm{Y}$ & $87.19+(-0.015) * \mathrm{SBP}+(0.35) * \mathrm{BW}$ & 3.1253 & 12.243 & 1.2172 & 0.1517 & Insignificant \\
\hline $\mathrm{Y}$ & $92.28+(-0.038) * \mathrm{DBP}+(0.62) * \mathrm{BW}$ & 4.0434 & 22.823 & 3.2011 & 0.0162 & Insignificant \\
\hline $\mathrm{Y}$ & $61.12+(-0.325) * \mathrm{MAP}+(0.23)$ * BW & 3.3223 & 13.253 & 1.2143 & 0.2352 & Insignificant \\
\hline
\end{tabular}


Table 6

Multiple Regression that Estimates OSL from SBP, DBP and MAP in Term Neonates, Given Body Weight

OSL Reg. Eqn. SEM t-stat $\mathrm{p}$-value $\mathrm{R}^{2} \quad$ Remark

\begin{tabular}{|cllllll|}
\hline \multicolumn{9}{|c}{$\mathrm{Y}=\mathrm{b}_{\mathbf{0}}+\mathrm{b}_{\mathbf{1}} \mathbf{x}_{\mathbf{1}}+\mathrm{b}_{2} \mathrm{x}_{2}$} \\
$\mathrm{Y}$ & $83.52+(0.006) * \mathrm{SBP}+(0.13) * \mathrm{BW}$ & 4.1232 & 11.224 & 0.2123 & 1.1321 & Insignificant \\
$\mathrm{Y}$ & $82.28+(0.013) * \mathrm{DBP}+(0.12) * \mathrm{BW}$ & 3.1221 & 10.122 & 0.4001 & 0.2262 & Insignificant \\
$\mathrm{Y}$ & $62.12+(0.001) * \mathrm{MAP}+(0.21) * \mathrm{BW}$ & 3.1224 & 9.232 & 0.2040 & 1.2522 & Insignificant \\
\hline
\end{tabular}

$S B P=$ Systolic Blood Pressure, $D B P=$ Diastolic Blood Pressure, MAP = Mean Arterial Pressure and OSL $=$ Oxygen Saturation Level; $Y=$ Predicted Neonatal Serum Variable (SBP, DBP or MAP), $b_{0}=$ regression intercept (constant), $b_{1}=$ regression coefficient for predicted marker (Constant), $b_{2}=$ regression coefficient for Pre-term neonate's body weight (Constant), $x_{1}=$ known levels of assayed marker [SBP, DBP or MAP], and $x_{2}=$ Known Neonate's Body Weight $(\mathrm{Kg})$.

\subsection{Prediction of OSL and RR from Neonatal pulmonary Parameters in Pre-Term Neonates using multiple linear regression}

In predicting or estimating RR from neonatal pulmonary measurements in pre-term neonates, a multiple linear regression analyses were carried out. It was observed that the significant correlation $(r=4.1760$, $p=0.0052 ; p<0.05)$ was obtained when neonatal OSL were entered in multiple linear regression analysis. Accordingly, on multiple linear regression analysis, OSL had significant correlation with $\mathrm{RR}(p<0.05)$, whereas RR had no significant correlation with OSL $(p>0.05)$. Therefore, the most important significant correlation was obtained from OSL (OSL $=r=4.1760, p=0.0052 ; p<0.05)$. Interestingly, the best regression model to predict RR of pre-term neonate was $=-\mathrm{RR}(\mathrm{BPM})=99.44+[0.018 \times \mathrm{OSL}](r=4.1760, p=0.0052$; $p<0.05)$ (Table 7).

Table 7

Multiple Regression that Estimates OSL and RR in Pre-Term Neonates, Given Body Weight

\begin{tabular}{|lllllll|}
\hline $\begin{array}{l}\text { OSL or } \\
R R\end{array}$ & Reg. Eqn. & SEM & t-stat & $\begin{array}{l}\text { p- } \\
\text { value }\end{array}$ & $\mathrm{R}^{2}$ & Remark \\
\hline $\mathrm{Y}(\mathrm{RR})$ & $\begin{array}{l}99.44+(0.018) * \mathrm{~b} \mathrm{~b}_{0}+\mathrm{b}_{1} \mathrm{x}_{1}+\mathrm{b}_{2} \mathrm{x}_{2} \\
* \mathrm{BW}\end{array}$ & & & & & \\
\hline $\mathrm{Y}(\mathrm{OSL})$ & $\begin{array}{l}102.46+(-0.038) * \mathrm{RR}+(3.97) \\
\text { * } \mathrm{BW}\end{array}$ & 8.5161 & 12.032 & 2.7922 & 0.0398 & Insignificant \\
\hline
\end{tabular}

Pressure and OSL = Oxygen Saturation Level, RR = Respiratory Rate; $Y=$ Predicted Neonatal Serum

Variable (OSL or $R R$ ), $b_{0}=$ regression intercept (constant), $b_{1}=$ regression coefficient for predicted marker (Constant), $b_{2}=$ regression coefficient for Pre-term neonate's body weight (Constant), $x_{1}=$ known levels of assayed marker [OSL or RR], and $x_{2}=$ Known Neonate's Body Weight (Kg). 


\subsection{Prediction of OSL and RR from Neonatal pulmonary Parameters in Term Neonates using multiple linear regression}

In predicting or estimating RR from neonatal pulmonary measurements in term neonates, a multiple linear regression analyses were carried out. It was observed that the significant correlation $(r=10.2529$, $p=00.0022 ; p<0.05)$ was obtained when neonatal OSL were entered in multiple linear regression analysis. Accordingly, on multiple linear regression analysis, OSL had significant correlation with $\mathrm{RR}(p<0.05)$, whereas RR had no significant correlation with OSL $(p>0.05)$. Therefore, the most important significant correlation was obtained from OSL (OSL $=r=10.2529, p=00.0022 ; p<0.05)$. Interestingly, the best regression model to predict RR of term neonate was $=-$ RR $(B P M)=11046+[0.023 \times 0 S L](r=10.2529$, $p=00.0022 ; p<0.05)$ (Table 8).

Table 8

Multiple Regression that Estimates OSL and RR in Term Neonates, Given Body Weight

\begin{tabular}{|lllllll|}
\hline $\begin{array}{l}\text { OSL or } \\
R R\end{array}$ & Reg. Eqn. & SEM & t-stat & $\begin{array}{l}\mathrm{p} \text { - } \\
\text { value }\end{array}$ & $\mathrm{R}^{2}$ & Remark \\
& $\mathrm{Y}=\mathrm{b}_{0}+\mathrm{b}_{1} \mathrm{x}_{1}+\mathrm{b}_{2} \mathrm{x}_{2}$ & & & & & \\
\hline $\mathrm{Y}(\mathrm{OSL})$ & $\begin{array}{l}94.21+(0.021) * \mathrm{RR}+(3.01) * \\
\mathrm{BW}\end{array}$ & 18.3322 & 3.1244 & 0.1328 & 1.0103 & Insignificant \\
\hline $\mathrm{Y}(\mathrm{RR})$ & $\begin{array}{l}11046+(0.023) * \mathrm{OSL}+(1.01) \\
\text { * } \mathrm{BW}\end{array}$ & 10.2529 & 2.0125 & 0.0022 & 1.2633 & Significant \\
\hline
\end{tabular}

Pressure and OSL = Oxygen Saturation Level, RR = Respiratory Rate; $Y=$ Predicted Neonatal Serum Variable (OSL or $R R$ ), $b_{0}=$ regression intercept (constant), $b_{1}=$ regression coefficient for predicted marker (Constant), $b_{2}=$ regression coefficient for Pre-term neonate's body weight (Constant), $x_{1}=$ known levels of assayed marker [OSL or RR], and $x_{2}=$ Known Neonate's Body Weight (Kg).

\subsection{Predictive Accuracy Measure of the Regression Model}

Based on the predictive biomarkers of the regression model, the individual parameters (e.g. MAP and $\mathrm{OSL}$ ) as indicated in model 1 had better predictive potential for pre-term neonate survival whereas the best predictor for term neonate are SBP and OSL (Model 2) as statistically correlated with RR (Table 9). 
Table 9

Regression Model Predictive Accuracy

Measurements for neonatal survival

\begin{tabular}{|l|}
\hline MODEL 1: \\
Regression model for pre-term neonates \\
\hline $\mathrm{RR}(\mathrm{BPM})=18.21+[0.011 \times \mathrm{MAP}]+(-0.06) \times \mathrm{BW}$ \\
$\mathrm{RR}(\mathrm{BPM})=99.44+[0.018 \times \mathrm{OSL}]+(4.00) \times \mathrm{BW}$ \\
\hline MODEL 2: \\
Regression model for term neonates \\
$\mathrm{RR}(\mathrm{BPM})=41.05+[0.012 \times \mathrm{SBP}]+(1.10) \times \mathrm{BW}$ \\
$\mathrm{RR}(\mathrm{BPM})=110.46+[0.023 \times \mathrm{OSL}]+(1.01) \times \mathrm{BW}$ \\
\hline
\end{tabular}

\subsection{Discussion}

This study evaluated neonatal cardiopulmonary and anthropometric status as key predictive clinical biomarkers for neonatal survival. It created a model that can be used to predict physiological variables in term and preterm neonates based on known variables. The chances of neonatal survival are high if it falls within the normal range as defined by the World Health Organization (WHO) and low if it falls outside the normal range. The discussion thus centers around and highlights reports, both current and previous, relating to the physiological changes in selected cardio-pulmonary and anthropometric health indices of newborns within the first 28 days of extra-uterine life (neonates).

Blood pressure is classified as "high" (HBP) when the mean SBP exceeds $120 \mathrm{mmHg}$ or the DBP exceeds $80 \mathrm{mmHg} .{ }^{13}$ The average systolic and diastolic blood pressures of each participant neonate was within normal limits at baseline. This was expected as it was one of the selection criteria to exclude new born babies with any cardiovascular health complications and/or anomalies.

This study also showed a significant decrease $(\mathrm{p}<0.05)$ in average body weight of pre-term neonates compared with term neonate. This could be due to intra-uterine growth. Thus term neonates might have gained more weights due to long period of stay in-utero as earlier explained by.$^{14}$ Throughout the monitoring period, the drop in preterm newborn weight became more gradual when compared to the term neonates, as a significant increase in average body weight was noticed at some period in the normal term neonate used in present study. Newborn infants whose developments in-utero occasioned by intrauterine growth restriction (IUGR) are usually small-for gestational-age (SGA), a body weight < 3rd centile. ${ }^{15}$ Most IUGR infants are the consequence of utero-placental insufficiency that occurs during the third trimester. ${ }^{14}$ Consequently, the weight was affected so that the neonate appears wasted. These gestational insults often cause critical under-nutrition and impair musculoskeletal growth, resulting in a stunted neonate 
with reduced weight and length. ${ }^{14}$ Therefore the observed reduced body weight noted in preterm neonates in this study could have been as a result of utero-placental insufficiency also noted in an earlier study. ${ }^{15}$

Blood pressure is one of the commonest clinical methods of assessing circulatory status of humans. ${ }^{16}$ In this study, the Systolic Blood Pressure (SBP) and Diastolic Blood Pressure (DBP) were assessed and a comparison was made in these values in term and preterm neonates. Accordingly, there was a statistically significant increase $(p<0.05)$ in the blood pressure parameters (SBP and DBP) for pre-term compared to term neonates. Thus, this current study deduced SBP as a key cardiovascular health marker which is revealed to be higher in preterm than term neonates. The DBP is apparently more crucial, and therefore having this lowering ability is more beneficial. Hence, modification for the prevention and management of high blood pressure is needed in preterm than term neonate. Considering all these, preterm neonates could be assumed to have a more chaotic (or less linear) cardiovascular function behavior than term neonates. The preterm neonates, who have no well-balanced sympatheticparasympathetic systems, can also be considered "less healthy" within the concept of health and disease. This logic is explained easily due to some intrinsic or extrinsic factors that must occur to justify delivery before the term ( $<37$ weeks of gestation). It is also expected that differences in age and the presence or absence of co morbidities changes the results of the assayed variables (SBP and DBP) used in assessing the standard cardiovascular patterns in this study. This finding corroborate previous study by. ${ }^{17}$

The pulse rate (PR) significantly affects cardiovascular function, and it is a vital marker for neonatal cardiovascular risk assessment. ${ }^{9}$ In this study, the PR was seen to have significantly increased $(p<0.05)$ in preterm than term neonates upon comparison. This depicts its immense benefit in reducing cardiovascular risk in term than preterm babies. This finding agrees with that from a similar study by 18 where there was no significant difference in PR with time for term babies.

In clinical practice, preterm neonates are closely monitored for diseases and related complications. As long as the "low-risk" neonates born at term appear well, they are subjected to the bare minimum of standardized observations. ${ }^{19}$ Unexpected diseases in term neonates, on the other hand, are normal and can quickly become life-threatening shortly after birth. ${ }^{20,21,11}$

Tachypnea, a condition characterized by respiratory rate higher than normal (RR) is used a symptoms of various diseases in the immediate neonatal period. ${ }^{22}$ Results from this study shows a statistically significant increase in RR of preterm compared with term neonates. By implication, this is suggestive of a high risk factor for preterm babies, specifically in the respiratory system. The increased work of breathing seen in preterm neonates in this study may be attributed to mismatched pulmonary mechanics. It may also be due to increased airway resistance (Pressure/Volumetric Flow), decreased lung compliance (Volume/Pressure), or both as earlier explained by ${ }^{23}$

Naturally, neonates undergo key physiologic changes during transition from intrauterine to extra-uterine life. ${ }^{10}$ In most cases, this transition is smooth. About $5-10 \%$ reportedly requires breathing supports, and 
about $1 \%$ requires absolute resuscitation. ${ }^{10}$ The indications and timing of supplemental oxygen therapy to assist the newborn in this transition has been a matter of debate. ${ }^{11}$ The 2010 International Liaison Committee on Resuscitation (ILCOR) recommendations states resuscitation can be initiated with room air or blended oxygen, but it should be guided by measurement of oxygen saturation using pulse oximetry. ${ }^{11}$ The target saturation was established to fall within the interquartile range of preductal saturations measured in healthy term babies following vaginal birth at sea level. ${ }^{11}$ In this current study, there was a statistically significant decrease OSL in preterm neonates compared to term neonates $(p<0.01)$. The mean time taken for the pre-ductal saturation to reach $90 \%$ was 7.4 minutes and for post-ductal 9.5 minutes. The mean time taken for equalization of pre and post- ductal saturation was 11.46 minutes with no significant correlation with time. Furthermore, about $74 \%$ of the term neonates had equalization of pre and post ductal SpO2 values over time. It is however shown that preterm neonates have lower SpO2 values when compared to term neonates, and they take a longer time to attain $\mathrm{SpO} 2$ values of more than $85 \% .{ }^{24}$ Furthermore, this study shows that the time taken for a preterm neonate to reach maximum SpO2 delivery is more than that required for term neonates, corresponding to the explanation of on the subject matter. ${ }^{24}$ This study also supports the hypothesis that preterm babies may have lower SpO2 compared to term babies, and they take longer time to achieve normal saturation.$^{25}$ It may be noted that the International Liaison Committee on Resuscitation (ILCOR) guidelines make no recommendations for using different time cut offs for these neonates ${ }^{26}$ However, we suggest that routine pulse oximetry is performed on neonates until weeks after birth for proper monitoring of the cyanosis and related condition.

In terms of anthropometric measurements, the current study found that birth weight, length, and head

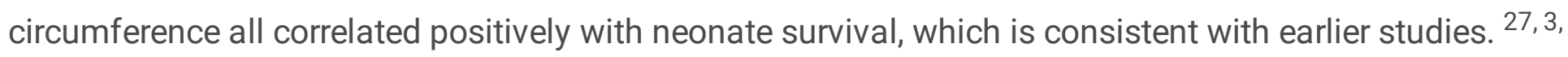
$28,29,30$,

Based on the predictive biomarkers of the regression model, the MAP and OSL had better predictive potential for pre-term neonate survival whereas the best predictor for term neonate are SBP and OSL which are statistically correlated with RR as shown in the results. Interestingly, significant correlation was observed for all the cardiopulmonary and anthropometric variables. Thus, all the parameters in this study are reliable to predict neonatal survival. This study formulated regression modeling equations from cardiopulmonary and anthropometric parameters to predict neonatal survival. Notably, statistically significant regression equation was derived with MAP and OSL as independent variables in preterm neonates, while SBP and OSL are independent variables in term neonates. However, RR seems to be the most reliable dependent variable for both preterm and term neonates. The calculated RR within normal limit in both term and preterm neonates predicts a higher chance of survival, while calculated RR outside normal limits in both term and preterm neonates predicts lower chances of survival. To the best of our knowledge, no research work has formulated a regression model predictive accuracy measurements for neonatal survival using a combination of neonatal cardiopulmonary and anthropometric parameters. Hence, this finding could be useful by community health workers to provide insight into the extent of 
compromise in the newborn health. More so, prediction of neonatal cardiopulmonary and anthropometric status is crucial to ensuring better treatment protocol/regimen

\section{Conclusions}

The study concluded that anthropometric measurements as well as cardiopulmonary indices are good predictors of neonatal survival. There was a decrease in RR and SpO2 in preterm neonates, indicating increased work of breathing and cyanosis, respectively. As a result, the knowledge of newborn cardiopulmonary and anthropometric variables may be effective predictive markers for early discovery of neonates that are at high risk of neonatal death, triggering earlier and more drastic care. A corroborative study with an event-driven approach that assays more molecular or other non-physiological variables is recommended.

\section{Declarations}

\section{Ethics approval and consent to participate}

Ethical approval was sought from the "Ethics and Research Committee", Central Hospital Warri (Protocol Number: CHW/ECC Vol 1/213) and the "Research, Ethics and Grant Committee", Faculty of Basic Medical Sciences, Delta State University, Abraka, Nigeria (Reference Number: REC/FBMS/DELSU/20/79). An informed consent was obtained from mothers of neonates included in this study. All methods were performed in accordance to the guideline provided by the ethical committees

\section{Consent for publication}

Not required

\section{Availability of data and materials}

Data obtained from this study is available on request from the corresponding author and Olowe G.T.

\section{Competing interests}

The authors declare that there is no conflict of interest of any form

\section{Funding}

The research was funded by the authors

\section{Authors' Contributions}

OSI and OEI conceptualised, designed and supervised the research, OGT and NBC conducted the research, OOM provided analytical tools and analyzed the data, EV prepared the manuscript, while all authors read and approved the manuscript 
A Special thanks to all technical staff of the Department of Physiology, Delta state University, Abraka.

\section{References}

1. Bhutta ZA, Hafeez A, Rizvi A, Ali N, Khan A, Ahmad F, Bhutta S, Hazir T, Zaidi A, Jafarey SN. "Maternal and child health in Pakistan: challenges and opportunities". The Lancet., 2019; 381: 3-5

2. Lawn JE, Cousens SN, Wilczynska K. "Estimating the causes of four million neonatal deaths in the year". International Journal of Epidemiology 2020; 35(3): 706-718

3. Tiruneh C, Teshome D. Prediction of Birth Weight by Using Neonatal Anthropometric Parameters at Birth in Finote Selam Hospital, Ethiopia. Pediatric Health Med Ther. 2021;12:259-267

4. Garne E, Haeusler M, Barisic I, Gjergja R, Stoll C, Clementi M. “Congenital diaphragmatic hernia: evaluation of prenatal diagnosis in 20 European regions. Ultrasound Obstet Gynecol 2012 19(4): 329-333.

5. Pattinson R, Kerber K, Waiswa P, Day LT, Mussell F, Asiruddin SK., Blencowe H, Lawn JE. "Perinatal mortality audit: counting, accountability, and overcoming challenges in scaling up in low- and middle-income countries". International Journal of Gynecology \& Obstetrics 2019; 107 Suppl 1:S11321, S121-2

6. Azevedo IG, Holanda NSO, Arrais NMR, Santos RTG, Araujo AGF, Pereira SA. Chest circumference in full-term newborns: how can it be predicted? BMC Pediatr. 2019;19(1):341

7. National Planning Commission [Nigeria]. 2012. Executive extract: Nutrition division adoption by the Federal Executive Council, 2012. Abuja, Nigeria: National Planning Commission.

8. Balogun JA, Obajuluwa BA, Olaogun MO, Abereoje OK, Oyeyemi AY, Adeodu OO, Balogun MO. "Anthropometric determinants of resting blood pressures and heart rates of Nigerian school children". Annals of Tropical paediatric 1990; 10(4):425-431

9. Athanase DP, Charalambos V, Frederique T, Yi Z, Bruno P, Jacques B, Michel ES. "Longitudinal Changes in Mean and Pulse Pressure, and All-Cause Mortality: Data From 71,629 Untreated Normotensive Individuals". American Journal of Hypertension 2017; 30(11): 1093-1099

10. Baldwin, Dees E. Embryology and physiology of cardiovascular system. In: Avery's Diseases of the Newborn 9th ed. Philadelphia: Elsevier Saunders 2012; 699713

11. Bancalari E, Claure N. Principles of respiratory monitoring and therapy. In: Avery's Diseases of the Newborn 9th ed. Philadelphia: Elsevier Saunders 2012; 612-632

12. Garber CE, Blissmer B, Deschenes MR, Franklin BA, Lamonte MJ, Lee IM, Nieman DC, Swain DP. American College of Sports Medicine position stand. Quantity and quality of exercise for developing and maintaining cardiorespiratory, musculoskeletal, and neuromotor fitness in apparently healthy adults: guidance for prescribing exercise. Med Sci Sports Exerc. 2011;43(7):1334-59. 
13. Panel E. Executive summary of the clinical guidelines on the identification, evaluation, and treatment of overweight and obesity in adults and Neonates. Archives of Internal Medicine 2008; 158(8), 18551867.

14. Beattie RB, Johnson P. "Practical assessment of neonatal nutrition status beyond birthweight: an imperative for the 1990s". International Journal of Obstetrics and Gynecology 2004; 101: 842-846

15. Olsen IE, Richardson DK, Schmid CH, Ausman LM, Dwyer JT. "The impact of early transfer bias in a growth study among neonatal intensive care units". Journal of Clinical Epidemiology 2013, 56(10): 998-1005.

16. Jones CM, Baker-Groberg SM, Cianchetti FA, Glynn JJ, Healy LD, Lam WY, Nelson JW, Parrish DC, Phillips KG, Scott-Drechsel DE, Tagge IJ, Zelaya JE, Hinds MT, McCarty OJ. Measurement science in the circulatory system. Cell Mol Bioeng. 2014;7(1):1-14.

17. Huikuri HV, Makikällio TH, Perkiomaki J. "Measurement of heart rate variability by methods based on nonlinear dynamics". J Electrocardiol 2013; 36: 95-99.

18. Phillipos E, Solevåg AL, Pichler G, Aziz K, van Os S, O’Reilly M., et al. “Heart Rate Assessment Immediately after Birth". Neonatology 2016 109(2):130-138

19. Benitz WE. "Hospital stay for healthy term newborn infants". American Academy of Pediatrics 2015; 135(5): 948-953

20. Finer N N, Barrington KJ.. "Nitric oxide for respiratory failure in infants born at or near term". Cochrane Database Syst Rev 2006; 4

21. Stoll BJ, Hansen NI, Sánchez PJ. “Early onset neonatal sepsis: the burden of group B Streptococcal and E. coli disease continues". Journal of the American Academy of Pediatrics 2011; 128(2): 390

22. Reuter S, Moser C, Baack M. Respiratory distress in the newborn. Pediatrics in review 2014; 35(10), 417-429

23. Ellwein Fix L, Khoury J, Moores RR, Jr Linkous L, Brandes M, Rozycki HJ. Theoretical open-loop model of respiratory mechanics in the extremely preterm infant. PloS one 2018; 13(6), e0198425.

24. Harris A, Sendak MJ, Donham RT. "Changes in arterial oxygen saturation immediately after birth in the human neonate". J Pediatr 2016; 109(1):117-119

25. Dawson JA, Kamlin CO, Vento M, Wong C, Cole TJ, Donath SM, Davis PG. "Defining the reference range for oxygen saturation for infants after birth". Pediatrics 2010; 125(6): e13401347

26. Kattwinkel J, Perlman JM, Aziz K, Colby C, Fairchild K, Gallagher J, Hazinski MF.. “Part 15: neonatal resuscitation: 2010 American Heart Association Guidelines for Cardiopulmonary Resuscitation and Emergency Cardiovascular Care". Circulation 2010; 122 (18): S909-19

27. Goto E. Meta-analysis: identification of low birth weight by other anthropometric measurements at birth in developing countries. J Epidemio/2011; 21(5):354-362.

28. Elizabeth NL, Christopher OG, Patrick K. Determining an anthropometric surrogate measure for identifying low birth weight babies in Uganda: a hospital-based cross sectional study. BMC Pediatr 2013; 13(1):1-7. 
29. Hadush MY, Berhe AH, Medhanyie AA. Foot length, chest and head circumference measurements in detection of low birth weight neonates in Mekelle, Ethiopia: a hospital based cross sectional study 2017;17(1):1-8.

30. Chukwudi NK, Nwokeukwu HI, Adimorah GN. Use of a simple anthropometric measurement to identify low-birth-weight infants in Enugu, Nigeria. Global Pediatric Health, 2018; 5:2333794X18788174.

31. Eric V, Charles EM. "Relaxing the Rule of Ten Events per Variable in Logistic and Cox Regression". American Journal of Epidemiology 2006; 165(6): 1-9

\section{Figures}

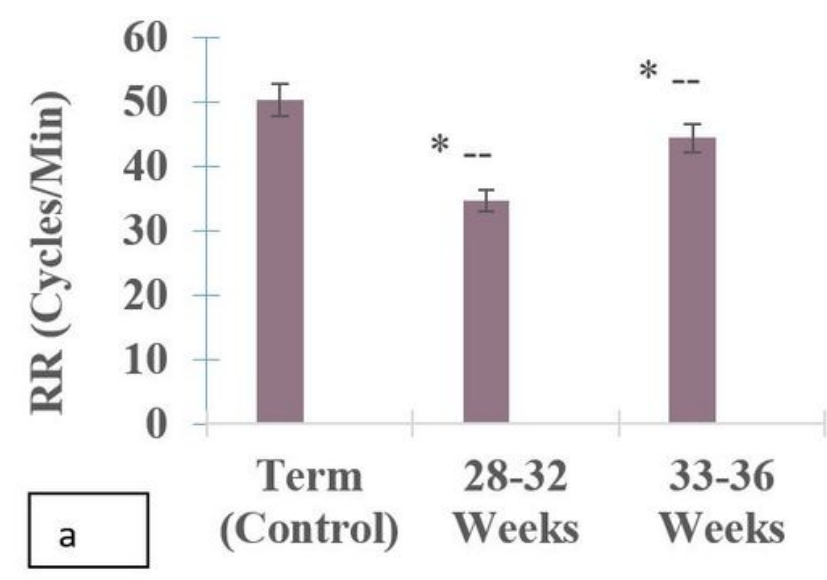

Gestational Age

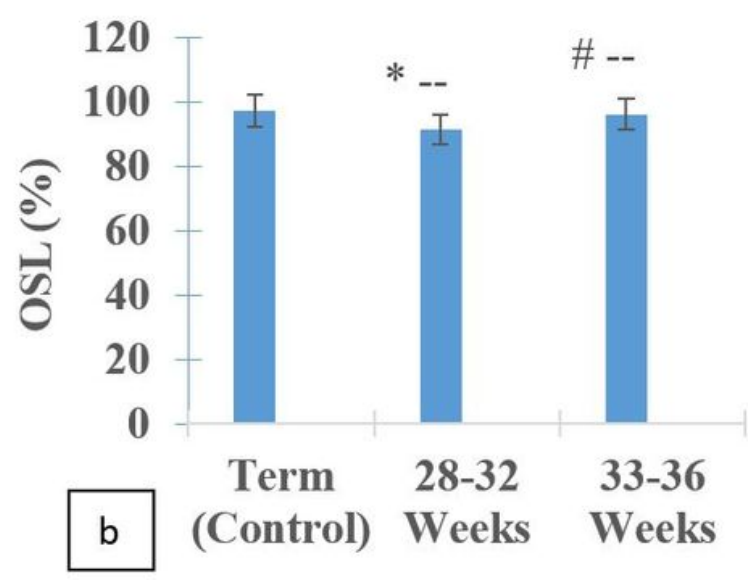

Gestational Age

\section{Figure 1}

a-b. Comparative Changes in Respiratory Rates of Term and Pre-Term Neonates respiratory rate, RR (b) and oxygen saturation level, OSL (b). Bars represent the mean \pm S.E.M $(n=80)$. One way ANOVA followed by Bonferroni's post-hoc test revealed that there are significant differences between various neonatal groups. *- = statistically significant decrease in OSL among pre-term neonates 28-32 weeks gestation compared to term (control) neonates at p-value < 0.05; \#-- = statistically insignificant decrease in OSL among pre-term neonates 33-36weeks gestation compared to term (control) neonates at $p$-value $<0.05$ 


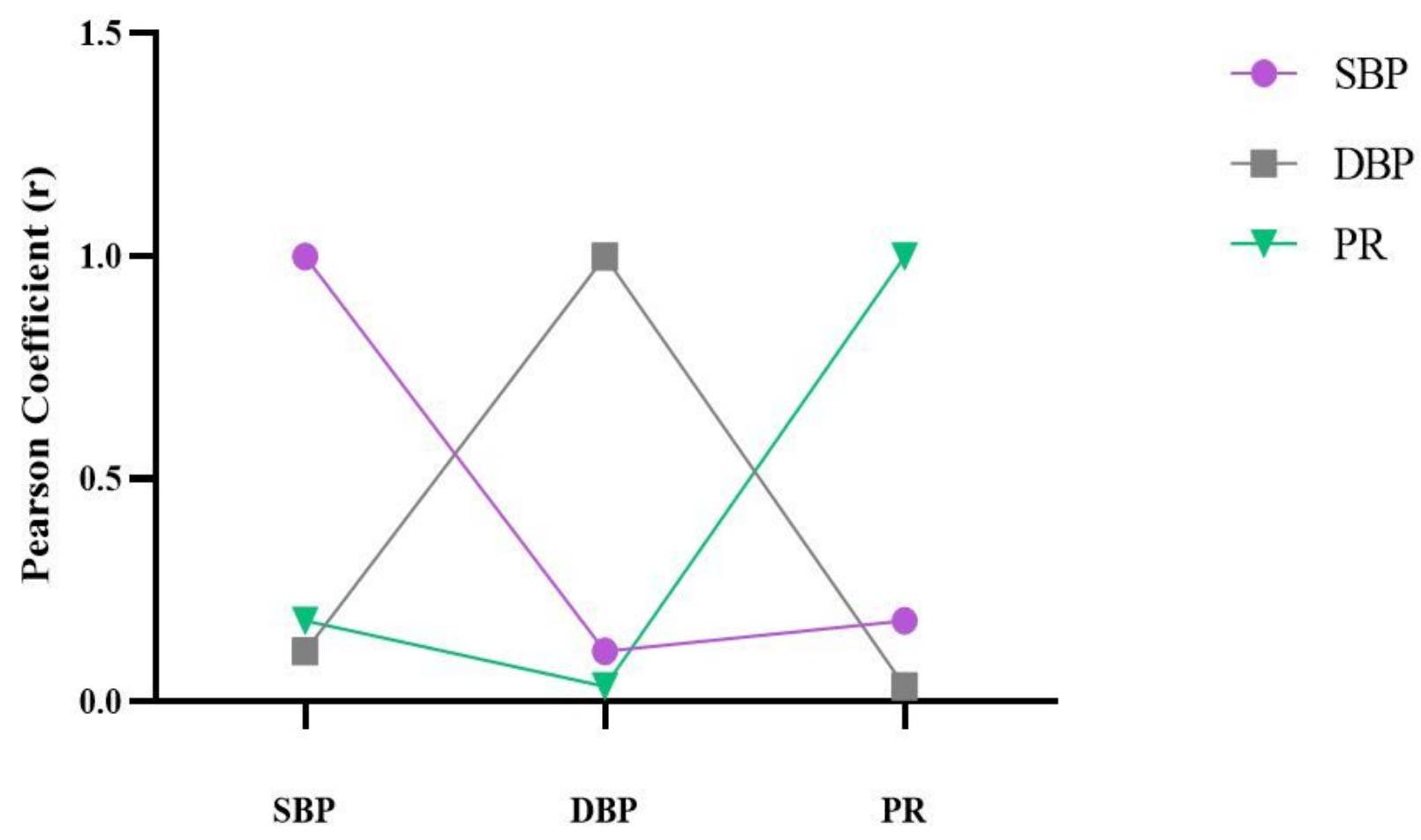

Cardiovascular Variables

Figure 2

Line graph revealing the relationship between SBP, DBP and PR in Neonates $r=1$ = perfectly correlated; $r<$ 0.5 or $>0.0=$ positively correlated; $r<0.0=$ negatively correlated. SBP $=$ Systolic Blood Pressure, DBP = Diastolic Blood Pressure, $\mathrm{PR}=$ Pulse Rate and $r=$ Pearson Product Moment Correlation Coefficient 


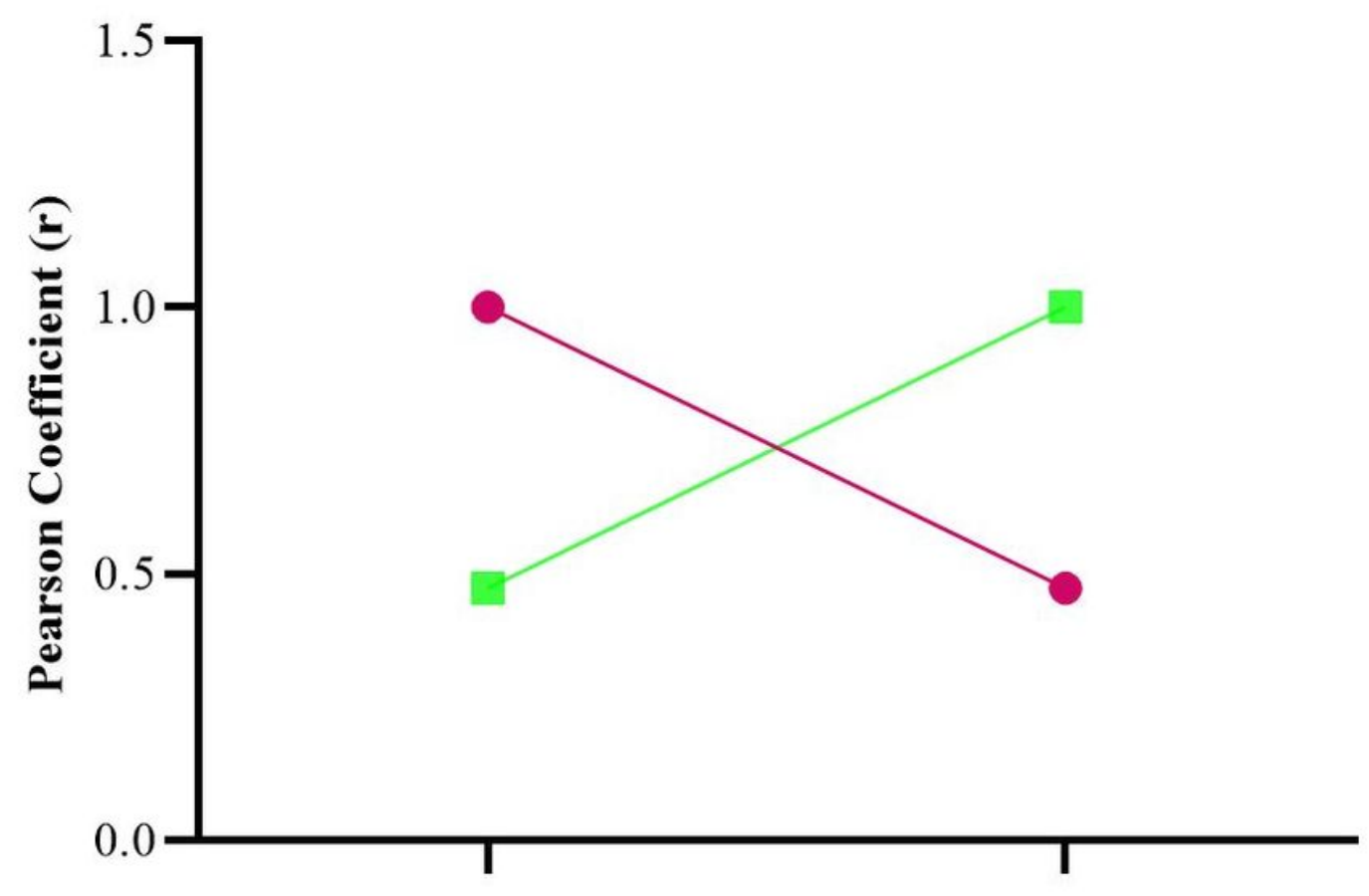

$\mathrm{RR}$

RR

OSL

\section{Respiratory Parameters}

\section{Figure 3}

Line graph revealing the relationship between RR and OSL in Neonates. RR = Respiratory Rate, OSL = Oxygen Saturation Level, and $r=$ Pearson Product Moment Correlation. Coefficient $r=1=$ perfectly correlated; $r<0.5$ or $>0.0=$ positively correlated; $r<0.0=$ negatively correlated 


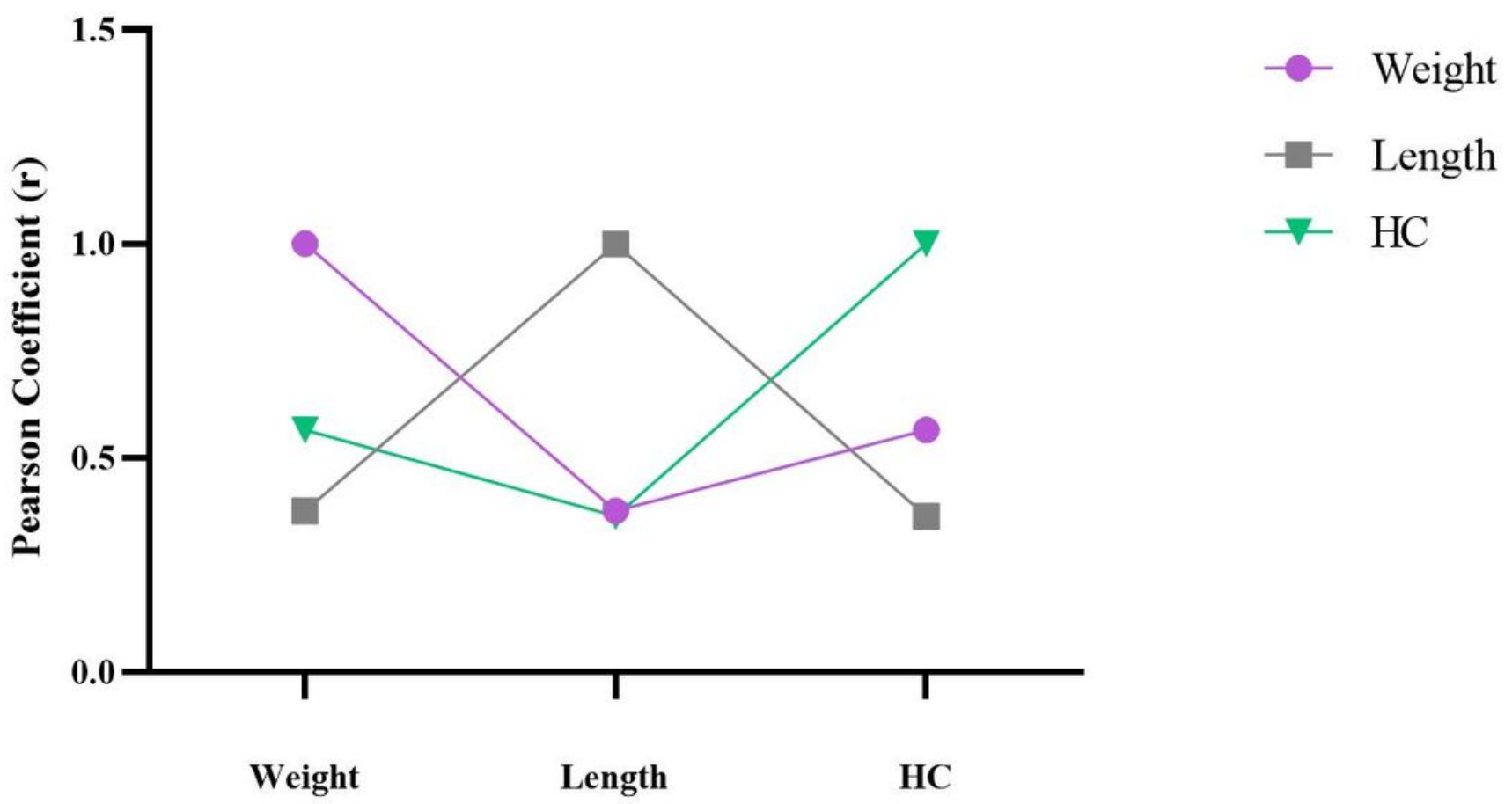

Anthropometric parameters

\section{Figure 4}

Line graph revealing the relationship between Weight, Length and $\mathrm{HC}$ in Neonates $r=1=$ perfectly correlated; $r<0.5$ or $>0.0=$ positively correlated; $r<0.0=$ negatively correlated. $\mathrm{HC}=$ Head circumference and $r=$ Pearson Product Moment Correlation Coefficient 